
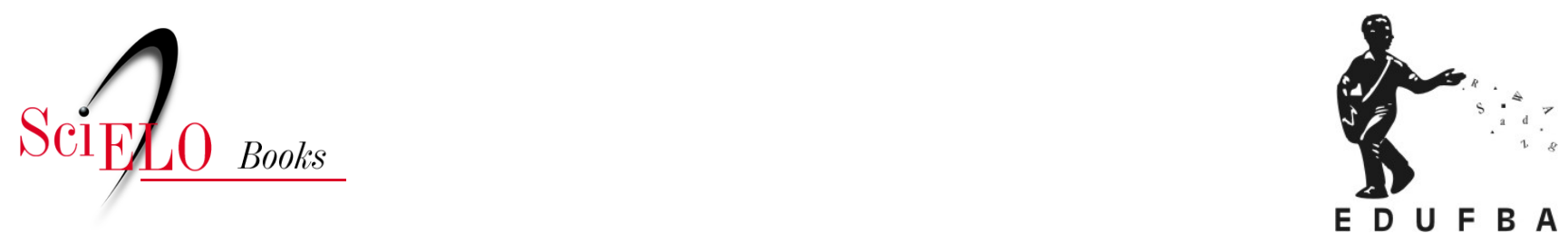

\title{
Pensar por margens
}

\author{
Thaís Troncon Rosa
}

ROSA, T.T. Pensar por margens. In: JACQUES, P.B., and PEREIRA, M.S., comps. Nebulosas do pensamento urbanistico: tomo I- modos de pensar [online]. Salvador: EDUFBA, 2018, pp. 176-204. ISBN 978-85-232-2032-7. https://doi.org/10.7476/9788523220327.0008.

All the contents of this work, except where otherwise noted, is licensed under a Creative Commons Attribution 4.0 International license.

Todo o conteúdo deste trabalho, exceto quando houver ressalva, é publicado sob a licença Creative Commons Atribição 4.0.

Todo el contenido de esta obra, excepto donde se indique lo contrario, está bajo licencia de la licencia Creative Commons Reconocimento 4.0. 
PENSA R PO R 


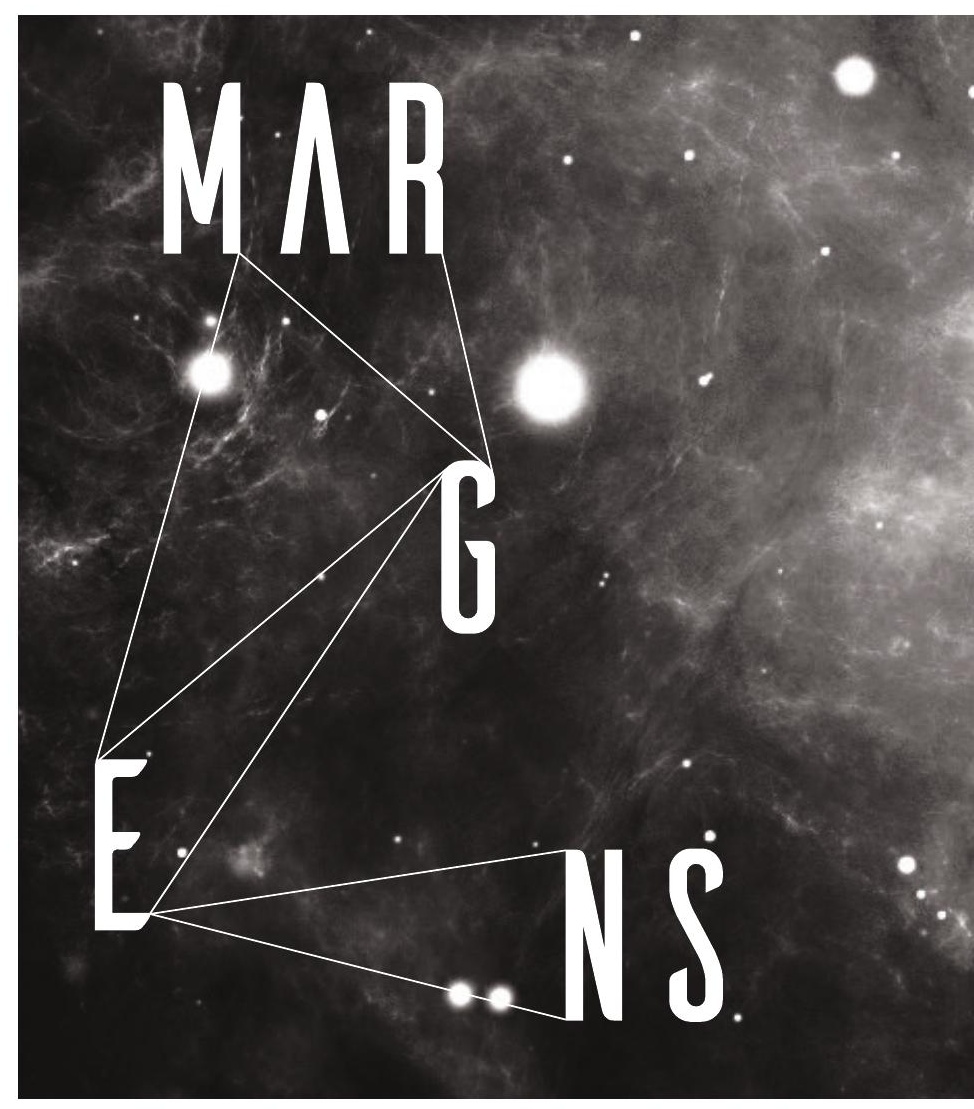




$$
\begin{aligned}
& \text { PENSAR } \\
& \text { P O H } \\
& \text { MA R G N S } \\
& \text { T H } \Lambda \text { IS }
\end{aligned}
$$

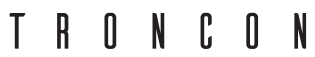

$$
\begin{aligned}
& \text { म O S } 1
\end{aligned}
$$


partir dos anos 1960, com o crescimento vertiginoso da população urbana no Brasil, a questão dos espaços de moradia das camadas populares nas cidades ganha visibilidade, especialmente através da multiplicação de favelas em algumas de suas principais capitais. Tomando tal questão como mote, todo um campo de estudos urbanos se consolidará no país, pautado, em um primeiro momento, pelo grande interesse despertado pelo tema da favela carioca e, posteriormente, pela análise das periferias que se espraiavam nas regiões metropolitanas, notadamente em São Paulo.

A construção de tal campo de estudos teria acompanhado as mudanças ocorridas nos cenários político e urbano brasileiros, sob influência, entretanto, de marcos teóricos específicos presentes no pensamento sociológico latino-americano nas décadas de 1960 e 1970. Assim, as primeiras abordagens de cunho acadêmico das favelas cariocas se fizeram no contexto do debate sobre a articulação entre a "teoria da marginalidade social" e a ideia de uma "cultura da pobreza", a partir da qual esses espaços foram interpretados como "a mais típica manifestação da não-integração” de parcelas significativas das camadas populares à cidade e à "sociedade urbana". (VEKEMANS; VENEGAS, 1966) Já os primeiros estudos acadêmicos sobre as periferias paulistanas representariam uma superação desse referencial, sob 
influência da teoria da acumulação capitalista, ${ }^{2}$ promovendo reflexões sobre a relação entre Estado, habitação e condições de reprodução da força de trabalho e encarando as periferias como espaços urbanos que, ocupados por trabalhadores pobres, seriam "socialmente homogêneos, esquecidos pelas políticas estatais e localizados tipicamente nas extremidades da área metropolitana". ${ }^{3}$ (TORRES et al., 2003, p. 98)

Além de consolidarem a favela e a periferia como objetos e campos de estudos urbanos, esses estudos pioneiros acabariam por promover sua conceituação, transformando-as em categorias de análise a partir das reflexões sobre a pobreza urbana e dos debates sobre moradia popular e a produção do espaço urbano no Brasil. Acompanhando os caminhos que promoveram tal construção conceitual das favelas e periferias no âmbito dos estudos urbanos, ${ }^{4}$ é possível apreender que, já na origem de ambos os conceitos, estariam presentes interpretações dicotômicas da cidade - manifestas inicialmente nas oposições cidade/favela e centro/periferia -, das quais esses fenômenos urbanos seriam "o avesso": territórios à parte, sem lei, sem Estado, sem urbanidade. Produzidos em sentido contrário aos discursos e práticas normatizadores da sociedade - urbanísticos, jurídicos, políticos, entre outros -, esses espaços seriam o extremo oposto da ordem e da formalidade da cidade.

Desde então, diversos - e importantes - trabalhos foram produzidos ao longo das décadas de 1960, 1970 e 1980 e, ao mesmo tempo em que desvendaram os processos sociais, culturais e de produção material e simbólica de tais fenômenos urbanos, construíram e formularam conceitos e categorias que, aos poucos, foram sendo incorporados ao debate público e, de certa forma, naturalizados na esfera acadêmica, tais como "cidade informal" ou "cidade ilegal". Consolidadas nos debates acadêmicos e políticos e legitimadas socialmente como "os espaços da pobreza nas cidades”, as favelas e periferias seriam mesmo indissociáveis da concepção dual - e hegemônica - da realidade urbana, que, no correr das últimas quatro décadas, se expressaria através de diferentes polaridades, "tais como formal-informal, integrado-excluído, favela-bairro, centro-periferia”, sempre tendo a questão da "ilegalidade" como um dos "critérios diferenciadores" 180 desses supostos pólos. ${ }^{5}$ 
A partir década de 1990, intensificaram-se, no debate público, tais concepções dualistas da cidade, em função, principalmente, do renovado interesse - não apenas acadêmico - pelo "problema da favela", com especial destaque para a metrópole carioca. A centralidade adquirida por temas como o tráfico de drogas e a violência urbana conferiria legitimidade social a tais concepções, que acabariam, de certa forma, por territorializar nas favelas a exclusão social, a violência e a ilegalidade urbana. Partindo da chave de leitura da exclusão, diversos estudos produzidos nesse contexto atestariam o agravamento dos contrastes socioespaciais entre os espaços de moradia das camadas populares na cidade - tipificados e associados quase genericamente às favelas - e "a cidade" em si, tornando-se frequentes nos debates públicos - não apenas cariocas -, desde então, as metáforas de "cidade partida", "apartheid socioespacial", bem como a associação desses espaços a "guetos", "enclaves", "bolsões de pobreza" etc. (RIBEIRO; LAGO, 2001; VALLADARES, 2005)

Nessa perspectiva, acentuaram-se aquelas interpretações das favelas e periferias a partir do que elas não têm. Ausência de leis, ausência do Estado, ausência de direitos, ausência de cidadania, ausência de ordem, ausência de planejamento - em última instância, ausência de cidade propriamente dita. Através da qualificação pela negação - que é um dos modelos teóricos bastante recorrentes nos estudos sobre "os pobres", "os trabalhadores", "as classes populares" - ${ }^{6}$ as favelas e periferias seriam compreendidas sempre em oposição àquilo que lhes seria negado e àqueles que os negariam - ou ainda a quem eles negariam, dependendo do referencial adotado: repõem-se, nas dicotomizações centro/periferia, asfalto/favela, as "oposições clássicas” - ou "falsas oposições" - que permeiam o pensamento social sobre os pobres, a pobreza urbana ou a cultura popular. ${ }^{7}$

O presente artigo é um desdobramento de uma senda investigativa que vem sendo construída por esta pesquisadora desde 2005, quando da aproximação ao campo da história, ${ }^{8}$ o qual se ancora, por um lado, na crítica à perspectiva totalizante de "cidade" que orientaria as concepções originárias - e seus desdobramentos contemporâneos - de "favela" e "periferia" e as abordagens dicotômicas sobre as cidades dela decorrentes, calcadas em categorias como "cidade 
informal" ou "cidade ilegal"; e, por outro, na crítica à perspectiva etnocêntrica que encararia tais configurações urbanas exclusivamente pela chave da ausência e que culminaria em proclamá-las "o avesso da cidade”: afinal, que cidade é essa que não estaria presente nos inúmeros espaços de moradia das camadas populares? Não seria a mesma cidade que os produz e que é também produzida por eles? E o que dizer da enorme parcela da sociedade que vive nesses espaços, das práticas, relações, disputas que os produzem e lhes dão sentido cotidianamente? Não seriam estes outros aspectos a serem considerados como forma de produção da cidade? Ao delimitar teoricamente fronteiras demasiadamente rígidas entre duas formas de produção da cidade - uma "formal", legalizada e exposta à sociedade e outra "informal”, "ilegal" e, no mais das vezes, considerada "periférica" -, tais abordagens não deixariam escapar a complexidade de relações que caracterizam, na prática, essas supostas fronteiras?

A partir de tais questionamentos, vimos nos aproximando de um amplo campo de debates que procura dar conta do quanto as mudanças em curso na economia e na sociedade, desde, pelo menos, o final dos anos 1980 e intensificadas a partir da segunda metade dos anos 1990, desestruturaram o "diagrama de relações" entre trabalho, cidade e política, a partir do qual se formularam aquelas reflexões pioneiras sobre a questão urbana no Brasil (RIZEK, 2003), embaralhando os pares conceituais que a pautavam e evidenciando uma "ampliada e crescente zona de indiferenciação entre o lícito e o ilícito, o direito e o não-direito, entre o público e o privado, a norma e a exceção”. Nesse contexto, diversos autores chamavam a atenção para a necessidade de se apreenderem as "realidades urbanas em mutação", uma vez que, a despeito da inegável existência das desigualdades e diferenças e de seu significativo aumento nos últimos anos, já há algum tempo, elas vêm se condensando em espaços múltiplos, redesenhados a partir de práticas, circuitos e relações que não cabem "nas dualidades supostas nos estudos anteriores”. (TELLES, 2006, p. 49, 61)

Em especial a partir dos anos 2000, uma gama diversificada de 182 trabalhos passou a introduzir questionamentos àquelas explicações 
gerais sobre "a crise urbana", bem como às definições categoriais de "pobreza”, “exclusão” ou "segregação". Desde então, esforços de reinterpretação das cidades desde os espaços e experiências urbanas das camadas populares vêm sendo empreendidos, mobilizando e articulando disciplinas, fontes, métodos dos mais variados. Se, por um lado, reatam-se criticamente fios das importantes abordagens produzidas nas décadas de 1970 e 1980, por outro, busca-se construir novos parâmetros do debate sobre os diversos fenômenos urbanos abarcados genericamente sob as noções de favela e periferia.

$\mathrm{Na}$ medida em que têm procurado apreender, descrever e analisar as insuspeitadas e velozes transformações pelas quais tais fenômenos vêm passando nas últimas décadas - e as práticas, os processos e os expedientes mobilizados em sua produção -, os conceitos e categorias antes acionados parecem já não dar conta da diversidade de realidades que continuam a nomear de forma genérica, evidenciando que dimensões da chamada "crise urbana" são também cognitivas.

Na tentativa de renovar e articular parâmetros críticos e parâmetros descritivos para pensar as transformações nas cidades contemporâneas brasileiras, ${ }^{10}$ nota-se, entre os trabalhos, um amplo debate sobre fontes, métodos e fronteiras disciplinares. A "prática restrita da interdisciplinaridade" (LEPETIT, 2001) é algo a destacar, em que a antropologia - e mais especificamente, a etnografia, enquanto perspectiva epistemológica -, é experimentada em interfaces com a sociologia, a ciência política, a psicologia social, a geografia, a economia, a arquitetura e o urbanismo. A atenção a categorias e representações "êmicas"; a apreensão, através de trajetórias individuais e familiares, de práticas, processos e expedientes mobilizados na produção do espaço urbano; a perspectiva relacional adotada para compreender tais fenômenos a partir dos cruzamentos, das mediações, dos agenciamentos, das relações que os produzem: eis alguns dos recursos mobilizados na tentativa de promover uma revisão analítica e conceitual do universo em questão, tarefa de grande envergadura que tem resultado em um esforço conjunto de pesquisa, em curso desde então.

Entretanto, se no contexto mais recente de intensificadas transformações urbanas no país, assentadas, em grande medida, nas dobras 
entre dimensões da financeirização e do empresariamento urbano e o acirramento da autoprodução de enormes parcelas das cidades pelas camadas populares, emergem rupturas em relação aos processos históricos de produção das cidades brasileiras, há também uma série de continuidades e permanências, nas quais se evidenciam processos de longa duração vinculados, sobretudo, às desigualdades e diferenças sob as quais tal produção se constitui. Dessa perspectiva, a produção, os usos, as apropriações da cidade pelas camadas populares, em seus atravessamentos de classe, raça e gênero, recobram seu lugar como componentes centrais da questão urbana contemporânea no país. (GLEDHILL; HITA; PERELMAN, 2017, p. 42)

É nesse sentido que emerge a perspectiva de um "olhar para a cidade a partir de suas margens” (AGIER, 2011; TELLES, 2013), ou do pensar por margens, como aqui proposto. A retomada contemporânea da noção de margens para pensar as "situações periféricas" (ALMEIDA; D’ANDREA; DE LUCCA, 2008) urbanas no país, tomando a "cidade como plano de referência" (TELLES, 2006), distancia-se em muito daquela já mencionada articulação entre a teoria da marginalidade social e a ideia de uma cultura da pobreza, a partir da qual se fizeram as primeiras reflexões acadêmicas sobre as favelas no Brasil. Assumindo o viés crítico e político da noção, tais reflexões contemporâneas recusam-se a pensar as margens na chave da ausência ou da exclusão, pensando-as relacionalmente e em perspectiva multiescalar: são encaradas em sua relação intrínseca com o "centro", são os "supostos necessários" do Estado, da sociedade, da cidade. (DAS; POOLE, 2004; FELTRAN et al., 2011)

Birman (2013, p. 7), em apresentação à coletânea de artigos organizada por Cunha e Feltran, propõe considerar

os lugares construídos como 'periféricos', mas sem buscar fixá-los a priori (por meio de atributos sociais, pelo estatuto de seus habitantes ou outros exames que desconsideram as formas variadas de inserção nesses espaços). 
Ao que eu acrescentaria também as formas variadas de produção e apropriação dos mesmos. Destacando o já mencionado processo coletivo de "elaboração rica de um campo analítico, cuja complexidade se deve ao reconhecimento de que as fronteiras das periferias estão longe de se constituírem por coordenadas somente ou primordialmente espaciais" (BIRMAN, 2013, p. 7), a autora evoca, em diálogo com os artigos da coletânea, a noção de margens, enfatizando que estas podem ser "políticas, religiosas, sociais, administrativas, culturais sem que se recubram de forma a criar espaços fixos, homogêneos, unificados e submetidos às mesmas clivagens". (BIRMAN, 2013, p. 7)

Trata-se, nesse sentido, de uma perspectiva que propõe pensar além do modelo espacial centro-periferia e, ao direcionar o foco para as margens, permite evidenciar novos nexos e relações de sentido frente às dinâmicas socioespaciais em curso, colocando-as no centro das reflexões sobre as cidades brasileiras. ${ }^{11}$

Tal perspectiva pode ser aproximada a um vasto e recente campo de reflexões, de âmbito internacional, em torno da noção de margens, de suas implicações simbólicas e materiais complexas e de sua ambiguidade em relação às fronteiras, a partir de reflexões sobre a reconfiguração geopolítica do mundo contemporâneo e os contextos de migrações internacionais, deslocamentos forçados e expulsões que a conformam. Conforme aponta Agier (2016), o mundo atual se faz, em grande medida, de mobilidades compulsórias, de contínuas buscas por moradia e pontos de fixação, de ancoragens cada vez mais incertas. ${ }^{12}$

Atestando a proliferação contemporânea das margens a partir de um processo contínuo de expansão de fronteiras pela globalização capitalista, cuja manutenção e perpetuação dependem, em grande medida, das práticas, sujeitos, tempos e espaços que conformam as - e se conformam nas - margens, diversos autores atestam sua dimensão produtiva, seu papel estratégico e central na atual configuração mundial (AGIER, 2008, 2016; MEZZADRA; NEILSON, 2013): constantemente produzidas e deslocadas, são também frequentemente alvo de intervenção, em termos da "destruição criativa" (HARVEY, 2007) que anima o capitalismo contemporâneo, ancorado nas dobras do que se denomina "estado" e "mercado". 
Em que pese sua proliferação, as margens são reiteradamente invisibilizadas, deslegitimadas ou criminalizadas nas narrativas de modernização que delineiam historicamente o Estado e suas territorializações. Das e Poole (2004, p. 3, tradução nossa) propõem, em contraponto, repensar criticamente o Estado a partir de suas margens, refletindo sobre "como as práticas e políticas de vida nas margens moldam as práticas políticas de regulação e disciplinamento que constituem aquilo que chamamos 'o estado'”. Atestando a polissemia da noção de margens, estas são mobilizadas na coletânea organizada pelas autoras, em sentido tanto descritivo quanto crítico, e sintetizadas em três proposições conceituais mais recorrentes: margens da legalidade oficial; margens da legibilidade estatal - associadas à documentação escrita -; e margens da normalidade - relação entre corpos, lei e disciplina, tendo por referência o conceito de biopoder foucaultiano.

A partir da etnografia de práticas, lugares e linguagens consideradas à margem do estado-nação, as margens são pensadas não como espaço periférico, lugar-fora estático, mas como dinâmicas que perpassam e atravessam o Estado por dentro, num permanente jogo dentro/ fora. A apreensão desse movimento torna as margens centrais para compreender o Estado, justamente por instaurar uma ruptura em termos da modernidade hegemônica: as margens são bem mais do que espaços de desordem ou locais onde o Estado não pôde instaurar a ordem. Apontando a relação entre violência e funções ordenadoras do Estado como questão-chave para a reflexão sobre as margens, em que a patologização ou criminalização de populações, práticas e territórios - alvos dos paradigmas desenvolvimentistas/ modernizadores - se faz modus operandi da relação Estado-margens, os diversos trabalhos reunidos na coletânea evidenciam outro aspecto importante para a abordagem que aqui delineamos: as margens não são inertes, as margens são instituintes de formas alternativas de ação política, de formas locais de pluralidade legal, econômica e cultural, lugares onde racionalidades e normatividades outras são praticadas cotidianamente. As margens, portanto, estariam permanentemente tensionando e disputando a modernidade hegemônica, para além 186 dos momentos críticos e eventuais de resistência. 
As margens emergem, portanto, como dimensão central na experiência contemporânea, fazendo transbordar a noção de fronteira ao embaralhar as distinções entre dentro e fora, privado e público, legal e ilegal, norma e transgressão, soberania e exceção, identidade e alteridade: para além do ato de dividir e conectar, para além da linha que institui a fronteira - estabelecimento de limites -, esse entendimento de margens as associa a uma espécie de zona móvel, continuamente redefinida, não fixa, elástica, em constante formação, evidenciando sua dimensão processual e relacional. (MEZZADRA; NEILSON, 2013; WEIZMAN, 2007)

Nesse sentido, a partir da ideia, recorrente nos diversos autores aqui mobilizados e nas experiências etnográficas empreendidas em minhas próprias pesquisas, da indeterminação, incerteza e ambiguidade constitutiva das margens contemporâneas, nos aproximamos também da noção de limiar, tal como proposta por Walter Benjamim, em uma distinção rigorosa da noção de fronteira: mais do que conter e manter, delimitar e separar - como o faz a fronteira -, o limiar se configuraria como uma zona de transição, não estritamente definida, remetendo a fluxos e contrafluxos, lugares e tempos indeterminados e de extensão indefinida, "um entre, uma zona cinzenta que funde categorias e mistura oposições”. (RIZEK, 2012, p. 34) Situam-se entre a possibilidade de um futuro em aberto - zonas de transição - e o achatamento gestionário da vida - zonas de detenção.

A aproximação entre as noções de margens e limiares, que aqui apenas se esboça, ${ }^{13}$ parece ser fértil em termos do que aqui consideramos pensar a cidade a partir de suas margens, sobretudo em diálogo com Arantes (2000), que, refletindo sobre as cidades contemporâneas brasileiras, propõe a noção de "zonas limiares": lugares sociais conformados por uma diversidade de categorias e sujeitos sociais, territorialidades e sociabilidades que se superpõem e se entrecruzam de modo complexo, não apenas no espaço, mas também no tempo. Essas zonas resultariam de referenciais de tempo-espaço "produzidos nos conflitos e sociabilidades chamadas marginais”. Também Perlongher (1987) reflete em termos de "espaços intermediários da vida social", cujas territorialidades não são estritamente fixas e evidenciam passagens relacionais entre elas, conformando formas de "resistência à ordem 
social hegemônica". Ou, nas palavras de Ribeiro (2010), tais zonas limiares corresponderiam à criação de "instáveis territorialidades" em meio - ou por sobre - políticas urbanas excludentes e sua materialidade na cidade, as quais se associam à emergência de relações e tensionamentos entre diferentes racionalidades, normatividades e territorialidades nas cidades contemporâneas.

Os autores apontam para uma dimensão potencial dessas margens espaços intermediários, instáveis territorialidades, zonas limiares e os corpos e práticas que as conformam -, que residiria na possibilidade de dar novas conotações simbólicas ao suposto esvaziamento do espaço público nas cidades - ou a sua espetacularização -, ao abrigar disputas e conflitos constitutivos da dinâmica urbana contemporânea e fazer constituirem-se outras contratualidades e racionalidades nas grandes cidades brasileiras contemporâneas. (ARANTES, 2000, p. 108)

Não se trata, obviamente, de ignorar as múltiplas violências - físicas e simbólicas - que incidem sobre tais zonas, práticas e corpos, dentre as quais destacam-se políticas e gestões, práticas de planejamento e policiamento e suas reiteradas tentativas de normatização e de conversão de limiares em fronteiras, cuja "transposição sem acordo prévio ou sem controle regrado significa uma transgressão, interpretada no mais das vezes como uma agressão potencial”. (GAGNEBIN, 2014, p. 35) Entretanto, os três autores, ao direcionarem o olhar para a construção de vínculos sociais, de sociabilidades, de urbanidades outras em relação àquelas hegemonicamente normalizadas e normatizadas propõem encarar os múltiplos limiares como "enunciações que as práticas sociais podem construir - e efetivamente constroem - no espaço da cidade" (ARANTES, 2000, p. 129), ações possíveis frente aos mecanismos de nivelamento (e supressão) das diferenças e à discriminação e seleção deles decorrentes.

Tais ações possíveis são pensadas por Ribeiro (2010) como espécie de transcendência que germina na imanência: paradoxos e tensões decorrentes de tais políticas, gestões e violências que criariam oportunidades - ainda que contraditórias - para a tessitura de relações sociais, para conformação das urbanidades outras que aqui 18 8 nos interessam. Invocando as práticas de mediação aí implicadas, a 
autora propõe a noção de gestos-fio, os quais "costuram, com fios tênues e tentativos, fraturas e feridas produzidas pela ação dominante". (RIBEIRO, 2010, p. 30) Também Perlongher (1987) irá propor que se encarem as práticas que aqui nomeamos de limiares menos como desvios, oposições ou rupturas frente às "normas sociais dominantes" e mais como trânsitos, mediações, passagens, entre contiguidade e separação, entre pontos de ruptura e pontos de sutura, invocando também a metáfora e o gesto de costura possível desse campo social desde suas territorialidades, sociabilidades, racionalidades e normatividades outras.

Tais perspectivas se mostram significativas em termos de reflexões sobre as cidades brasileiras contemporâneas, sobretudo quando se considera que, entre arquitetos e urbanistas, parecem ainda prevalecer aquelas explicações gerais sobre "a cidade e sua crise", projeções quase sempre ancoradas em "totalidades inacessíveis de um ponto de vista empírico - a 'grande cidade', o 'urbano global', a 'metrópole', a 'urbanização desterritorializada”"14 (CORDEIRO; FRÚGOLI JUNIOR, 2011, p. 19) e, sobretudo, naquelas mesmas abordagens dicotômicas calcadas em categorias como informalidade, ilegalidade ou anomia, que seguem encarando as diversas dinâmicas socioespaciais e territorialidades não hegemônicas exclusivamente pela chave da ausência, da carência e legitimando intervenções e violências de toda ordem. Em contraponto, a cidade que emerge das pesquisas históricas e experiências etnográficas a partir das quais aqui refletimos se apresenta como campo de trânsitos e mediações em que se articulam - não sem conflitos - temporalidades, espacialidades e universos sociais distintos. ${ }^{15}$

Joseph (1999, p. 33-39), conferindo importância "à tomada de partido rigorosamente descritivo de uma etnografia do deslocamento", a qual possibilitaria apreender a própria "urbanidade em operação", fornece algumas pistas para pensar essa dimensão dos trânsitos e mediações que parecem ser constitutivos das margens, como aqui pensadas: seria possível pensar a cidade a partir das categorias da liminaridade, da passagem, da instabilidade, do espaçamento e da contiguidade? Ou, ainda, a partir da ideia de "um espaço descontínuo constituído de várias regiões de significação, com seus recursos cognitivos e nor- 
mativos próprios", articuladas entre si por eventos de mobilidade, cursos de ação singular?

Não se pretende afirmar, com isso, a inexistência de fronteiras socioespaciais a delimitar os territórios, as trajetórias e as experiências em foco nas investigações realizadas e em curso nas margens da cidade. Mas, ao atentar para margens e limiares, buscamos nos distanciar das dicotomias e categorias autoexplicativas - como segregação ou exclusão - e evidenciamos a perspectiva de que há dinâmicas socioespaciais em constante movimento, produzindo e disputando a cidade em suas margens e, portanto, deslocando-as continuamente.

Sem desconsiderar a polissemia da noção, bem como a heterogeneidade material e simbólica das margens, que configuram distintos sentidos a partir dos distintos espaços, tempos, práticas e corpos que as constituem em variadas situações sociais e territoriais, as dimensões aqui brevemente elencadas, que partem do diálogo com alguns autores e têm como plano de fundo pesquisas empíricas realizadas nas margens das cidades desde 2005, já nos dão pistas do quão férteis as margens podem ser em termos da investigação das dinâmicas urbanas contemporâneas, das cidades e também do urbanismo.

Entretanto, mais do que apreendê-las enquanto "categoria" ou "objeto" de investigação, as margens são aqui evidenciadas como perspectiva analítica para compreender as cidades contemporâneas e as disputas que as constituem: pensadas como processos, atentando ao que produz e como se produzem as margens - e, sobretudo, ao que elas produzem -, esse olhar para a cidade a partir de suas margens tem possibilitado novos campos de reflexão e problematização sobre o espaço urbano e seus modos de produção processual e conflitivo.

$\mathrm{Ou}$, se considerarmos o descentramento implicado nesse pensar por margens, bem como as questões e desafios que tal postura coloca aos modos de pensar e produzir conhecimento sobre as cidades e, consequentemente, às "categorias cognitivas e normativas que, por muito 190 tempo, primaram no campo dos estudos urbanos” (TELLES, 2013a), 
mais do que apontar para uma necessária renovação nas ferramentas teóricas e metodológicas, pensar por margens implica uma posição, a um só tempo, epistemológica e política. ${ }^{16}$

E aqui tangenciamos, em alguma medida, um conjunto de reflexões contemporâneas que tem problematizado a produção de conhecimento a partir das "margens do mundo", reivindicando o "sul global" como lócus de produção teórica, enfatizando as "fronteiras da diferença colonial" e recobrando outras perspectivas e dimensões da modernidade. Sem nos aprofundar nessa seara, que exigirá um desdobramento mais cuidadoso em outra oportunidade, ao considerarmos as margens como perspectiva epistemológica para pensar as cidades contemporâneas, faz-se inevitável uma aproximação - ainda em curso - a tais abordagens, sobretudo no que tange às concepções de "epistemologia fronteiriça", "pensamento liminar" e "pensamento crítico de fronteira", para citar algumas modulações dessas reflexões ${ }^{17}$ que apontam para disputas epistemológicas importantes, que se somam às outras muitas camadas de disputas que as margens encerram, como evidenciado anteriormente.

As questões aqui delineadas se alinham, portanto, a uma reflexão sobre o lugar do pensamento crítico e da produção do conhecimento, desdobrada a partir da atenção aos limiares e às alteridades inerentes às margens das cidades e às disputas aí implicadas. Trata-se, portanto, de uma proposição que as traz para o centro da análise, demandando à produção de conhecimento sobre as cidades uma perspectiva relacional:

O limiar designa, portanto, essa zona intermediária que a filosofia ocidental - bem como o assim chamado senso comum - custa a pensar, pois que é mais afeita às oposições demarcadas e claras (masculino/feminino, público/privado, sagrado/ profano etc.), mesmo que haja, em alguns casos, um esforço em dialetizar tais dicotomias. (GAGNEBIN, 2014, p. 37)

Partindo também de limiares disciplinares ou da já mencionada prática restrita da interdisciplinaridade, temos nos valido, em especial, dos cruzamentos entre os campos da arquitetura e do urbanismo, 
da história e da antropologia na construção desses outros modos de pensar as cidades e o urbanismo a partir de suas margens, que se ancoram na potência cognitiva e crítica da experimentação etnográfica, desdobrando-se metodológica e analiticamente em abordagens relacionais, situadas e multiescalares. Não caberia aprofundar tais desdobramentos metodológicos e analíticos, dados os limites deste texto, ${ }^{18}$ mas se faz necessário reiterar a dimensão do encontro, do compartilhamento e do diálogo que a etnografia implica: "a etnografia é em si um debate, um colocar em perspectiva diversos lugares de locução e escuta. Etnografar é um lançar-se ao outro, é gesto que incita deslocamentos de ideias e provações corporais". (RUI; MARTINEZ; FELTRAN, 2016, p. 16) Não se trata, necessariamente, de uma fala desde a experiência em si e, de modo algum, de um olhar externo a ela, mas sim do estabelecimento de uma interlocução etnográfica, da produção de um saber mútuo.

Também Ribeiro $(2010,2012)$ irá enunciar a prática de uma "episteme dialógica”, a qual se concretizaria numa implicação corpórea do pesquisador com as práticas dos "muitos outros" nas cidades e suas zonas limiares, na disposição ao encontro, ao diálogo, à compreensão de outras racionalidades e normatividades, de outros modos de pensar, fazer e viver, e, sobretudo, à partilha de saberes e produção conjunta de conhecimento com aqueles que habitam e produzem cotidianamente as margens da cidade:

Sem o contato com essas ações - cuja apreensão exige a valorização do instante, de códigos grupais e de linguagens corporais - o pensamento crítico abandona experiências que enlaçam energias sociais e preenchem o cotidiano, confeccionando tecido urbano novo. (RIBEIRO, 2010, p. 29)

Tomadas como perspectiva epistemológica, as margens não aparecem mais, portanto, como desvio ou expressão da "falta de ordem" urbana, mas evidenciam-se como constituintes - e mesmo como condições necessárias - de uma dada concepção - à qual corres192 ponde uma produção - de cidade, de urbanismo, de urbanização. 
Não se trata, portanto, de inverter a valoração sobre os processos e dinâmicas socioespaciais que as configuram - da negatividade para a positividade -, mas de mudar a perspectiva de apreensão sobre eles, desnormatizando seu campo de significação. Sem desconsiderar sua construção histórica como "problema urbano" ou "questão social", propomos produzir reflexividade sobre e desde as margens, evitando reificar tal dimensão "problemática" como um dado objetivo que estaria presente qualquer que fosse a situação ou o ângulo de análise.

Dessa forma, tencionamos moldar uma crítica da racionalidade gestionária e aprioristicamente interventora que orienta não apenas práticas, mas também pesquisas no campo da arquitetura e do urbanismo, ${ }^{19}$ estabelecendo um contraponto à abordagem das margens nos termos unívocos de sua valoração ou de sua transformação. $\mathrm{O}$ que se propõe aqui não tem como destino prévio a necessidade de intervenção, mas a produção de conhecimento: trata-se de compreender como se constituem, como funcionam, como são vividos e significados os processos e as dinâmicas socioespaciais em foco, e não de pensar exclusivamente como transformá-los ou como ordená-los.

Nesse sentido, as pesquisas que vimos desenvolvendo mais recentemente têm se proposto a pensar não apenas as cidades, mas também o urbanismo, a partir de margens e limiares, ${ }^{20}$ perscrutando dimensões socioespaciais e, sobretudo, os meandros da conformação de distintos "regimes de urbanidade" (AGIER, 2011, 2015) a serem considerados analítica e politicamente. Espera-se estabelecer uma reflexão ampliada sobre dinâmicas de produção do que vimos chamando "urbanidades liminares” em curso, contemporânea e historicamente, no país, possibilitando desnudar as aproximações e disjunções entre saberes e dispositivos técnicos de planejamento e gestão urbana (e social) e saberes, práticas e narrativas de produção de cidade e urbanidade em ato, alargando e fortalecendo campos de reflexão crítica que se somem aos ainda escassos estudos urbanos que vêm se atentando à existência de diferentes regimes de urbanidade e múltiplas maneiras de "fazer cidade". 


\section{NOTAS}

1 Para um panorama dessas abordagens, ver, dentre outros, Valladares (2005). Para um estudo sobre a contribuição e a crítica da teoria da marginalidade social, ver Perlman (1977). A concepção de uma "cultura da pobreza" foi proposta em Lewis (1959).

2 Tal ruptura terá como referência paradigmática o trabalho de Oliveira (1972), que ecoará por toda a década de 1970, influenciando significativamente os estudos subsequentes sobre as periferias urbanas. Poucos anos depois, a publicação de um conjunto de trabalhos de pesquisa sobre as condições de vida na cidade de São Paulo (KOWARICK; BRANT, 1975) fará circularem de forma mais ampla as proposições que articulavam acumulação e pobreza, introduzindo no debate as noções de periferia e de urbanização periférica. Caberia aqui, ainda, destacar alguns trabalhos pioneiros, como: Sampaio e Lemos (1978), Bonduki e Rolnik (1979), Maricato (1979), Valladares (1980), entre outros.

3 Para alguns breves balanços dessas interpretações, ver: Valladares (1983, 2005); Coraggio (1989); Kowarick (2000); Marques e Bichir (2001); Frúgoli Junior (2005). Diversos outros autores farão menção a esse momento do pensamento sociológico sobre as cidades no Brasil, frisando sua interlocução direta com o marxismo-estruturalista francês e, em especial, com as abordagens de Castells (1983) e Lojkine (1981).

4 No primeiro capítulo da dissertação de mestrado Fronteiras em disputa na produção do espaço urbano: a trajetória do 'Gonzaga' de favela a bairro de periferia (2008), percorri, de forma panorâmica, alguns dos caminhos tomados pelos estudos de favelas e periferias urbanas no Brasil desde sua "descoberta" social e acadêmica. A intenção foi recuperar alguns debates sobre tais fenômenos, no âmbito dos estudos urbanos - com especial destaque para a sociologia urbana de filiação marxista-estruturalista, a ciência política e a antropologia - desde sua construção enquanto problemas sociais, categorias, campos ou objetos de estudos, frisando as continuidades e descontinuidades ao longo dos períodos enfocados. As questões aqui apresentadas somente se fazem possíveis em razão dessa revisão crítica realizada anteriormente, a qual não caberia retomar em detalhes neste texto, dados os limites do mesmo.

5 Lago (2003, p. 2), Valladares (2005), Zaluar e Alvito (2003), Torres e colaboradores (2003) e Silva (2006). De fato, ao longo de todo o processo de urbanização brasileiro, a relação entre ilegalidade e pobreza tornou-se praticamente inexorável: a inserção das camadas populares no espaço urbano tem sido problematizada, em grande medida, pela questão da ilegalidade urbana, ou da 
difusão das favelas pelo espaço urbano -, mas também na cidade de São Paulo, as origens da constituição de uma "outra cidade" para além da "cidade legal" remontariam às primeiras décadas do século XX (ROLNIK, 1997), ainda que a questão tenha ganhado maior visibilidade apenas no momento em que a progressiva expansão das periferias atingiria dimensões extremas, entre as décadas de 1960 e 1970.

6 Veja-se reflexões nesse sentido em Caldeira (1984); Paoli, Sader e Telles (1983); Paoli e Sader (1986); Sarti (1994); Zaluar (1985); Coraggio (1989).

7 Zaluar e Alvito (2003) afirmam que as origens desse pensamento dualista sobre a cidade, no país, remontariam às representações, produzidas no século XIX, referentes à existência de "dois Brasis", um urbano e moderno e outro tradicional, rural, atrasado. Segundo os autores, "essa reflexão sobre a dualidade brasileira encontrou na oposição favela X asfalto uma de suas encarnações". (ZALUAR; ALVITO, p. 13)

8 Desenvolvi reflexão mais aprofundada sobre tais questões aqui apresentadas apenas brevemente em Rosa (2008, 2009).

9 Trata-se de questionar uma abordagem essencialista da cidade, na qual o conceito se apresenta como universal, naturalizado, e tudo o que escapa de ser englobado por ele configura-se em seu avesso ou sua ausência. Ver também nota 16.

10 "Duplo desafio: a construção de parâmetros críticos (e a reativação da tradição crítica das ciências sociais) implica, ao mesmo tempo, a construção de parâmetros descritivos para colocar em perspectiva realidades urbanas em mutação". (TELLES, 2006, p. 48)

11 Feltran (2010), em apresentação à edição especial da revista do CRH intitulada Margens, que reuniu alguns trabalhos que evidenciam o conflito político desde lugares e sujeitos considerados "marginais" - favelas, sertões, ruas e prisões; imigrantes ilegais, moradores de rua, pixadores, ladrões -, em seus embates cotidianos com sujeitos e lugares "legítimos" do mundo social, destaca o quanto as margens, sobretudo os "contingentes 'marginais' da população", têm estado no centro do pensamento social moderno - a partir de autores como Simmel e Foote-Whyte; Arendt, Foucault e Rancière; ou ainda dos subaltern studies e estudos pós-coloniais. Entretanto, os trabalhos contemporâneos dos quais a coletânea dá uma mostra, mais do que apenas enfocar populações, territórios e circuitos sociais invisibilizados socialmente ou considerados marginais, ou situar objetos de estudo na contramão do "legítimo", evidenciam, justamente, os nexos que se desenham entre esses mundos de práticas, a complexidade de conexões entre os espaços por onde os sujeitos transitam, "lançando luz interpretativa acerca de cotidianos, conflitos pessoais, poderes e discursos em disputa". 
12 Destacaria, nesse sentido, os chamados "border studies" (KOLOSSOV, 2005; MEZZADRA; NEILSON, 2013), ou o que Agier (2015, 2016) vem denominando uma "antropologia das/nas margens", para citar alguns exemplos. Importante ressalvar que a distinção entre fronteiras, margens, bordas, limites envolve variações linguísticas e etimológicas - caso das distinções, por exemplo, entre border, frontier, boundary, margin, edge, para ficar apenas no inglês -, que não caberiam ser aprofundadas aqui, bem como implicações conceituais e mesmo políticas que merecerão maior atenção em outra ocasião. De todo modo, dentre os autores aqui mobilizados, aqueles que se referem, por exemplo, à noção de border, o fazem de forma alargada, mencionando, por exemplo, border situations, borderscapes, border zones, cujas definições se aproximam da noção de margens, tal como desdobrada neste texto.

13 Uma reflexão sobre o limiar como perspectiva de reflexão sobre as cidades brasileiras contemporâneas foi esboçada anteriormente em Rosa e colaboradores (2017).

14 Evitando partir de tais totalidades inacessíveis, o esforço epistemológico daí decorrente se faz, entretanto, no sentido de não deslizar para uma perspectiva fragmentária, da cidade como mosaico ou reduzida a localismos, como alerta Smith (2002). Refletindo sobre o espaço geográfico de forma mais ampla, o autor, partindo da crítica a uma abordagem da diferença como totalidade - que se reduziria à diversidade - e dialogando com a proposição de Lefevbre da cidade como espaço das diferenças, conduz a reflexão em termos de uma concepção relacional do espaço - aí incluída a cidade - a partir de uma concepção também relacional das escalas espaciais. Há ainda toda uma reflexão, fundamental, sobre o quanto tal noção totalizante de cidade construiu-se a partir de um referencial eurocêntrico, sendo necessário aos estudos urbanos um descentramento cultural, como indica Agier (2017, p. 424): "Os saberes e imaginários atuais da cidade constituíram-se historicamente no mundo ocidental e só parcialmente correspondem à realidade múltipla dos fatos urbanos no mundo atual. O próprio conceito de cidade que foi construído em transparência com o modelo da cidade europeia, está fornecendo os marcos referenciais e as ordens de grandeza segundo os quais os estabelecimentos humanos do resto do planeta foram, e continuam sendo, medidos".

15 Ver, nesse sentido, Rosa (2014).

16 Conforme Agier (2015, p. 487): "Não a margem como fato social, geográfico ou cultural, mas a margem como posição epistemológica e política: apreender o limite do que existe - e que existe sob a aparência oficial e afirmada do realizado, do estabelecido, do ordenado, central e dominante - permite perceber a dialética do vazio e do cheio e descrever o que, a partir de quase nada ou de um estado aparentemente caótico, faz cidade”. 
17 Destacamos, nesse sentido, algumas dessas abordagens em âmbito latino-americano, a partir das aproximações ainda em curso em nossas pesquisas: Anzaldua (1987), Mignolo (2003a, 2003b), Mignolo e Tlostanova (2006), as coletâneas organizadas por Castro-Gómez, Guardiola-Rivera e Benavides (1999), Lander (2000), Moraña, Dussel e Jáuregui (2008) ou Borsana e Quintero (2014). Há ainda uma aproximação do campo do urbanismo e do planejamento urbano a esses debates, cujas ideias de um urbanismo subalterno, da informalidade como modo de vida ou da favela como teoria merecem reflexões críticas a serem desdobradas em outra ocasião. Ver, por exemplo: AlSayyad (2004), Roy (2005, 2011), Rao (2006) ou Varley (2013).

18 Ao que remeto novamente, a título de aprofundamento destas perspectivas aqui esboçadas, a Rosa (2014).

19 Tal perspectiva também estaria fortemente presente em pesquisas filiadas à chamada sociologia urbana, conforme esclarece Hirata (2010). O autor, em reflexão sobre a prática de pesquisa nas cidades e suas complexas relações com a gestão das populações urbanas, desenvolve uma crítica à postura gestionária frente aos chamados "problemas urbanos", a partir de uma revisão dos primeiros estudos da Escola de Chicago, nos quais se construiu a noção da cidade como laboratório e clínica do humano: "Ela parte da representação da cidade como laboratório social, onde seria possível identificar as variáveis que constroem o urbano como um meio, e tem como perspectiva a construção de uma estrutura pragmática, a cidade como artefato, em vista de um ordenamento ou um campo de intervenção possível do homem sobre o homem”. (HIRATA, 2010, p. 11-12)

20 Nas pesquisas em curso, por mim coordenadas, intituladas "Urbanidades Liminares: moradia e dinâmicas socioespaciais nas 'margens' da cidade" e "Cronologia do Pensamento Urbanístico - campo de debates sobre participação”, desenvolvidas no âmbito do grupo de pesquisa Laboratório Urbano, no Programa de Pós-graduação em Arquitetura e Urbanismo da Faculdade de Arquitetura da Universidade Federal da Bahia (PPGAU/FAUFBA). 


\section{REFERẼNCI IS}

AGIER, M. Antropologia da cidade: lugares, situações, movimentos. São Paulo: Terceiro Nome, 2011.

AGIER, M. Do direito à cidade ao fazer-cidade: o antropólogo, a margem e o centro. Mana, Rio de Janeiro, v. 21, n. 3, p. 483-498, 2015.

AGIER, M. Borderlands: towards an anthropology of the cosmopolitan condition. Malden: Polity Press, 2016.

AGIER, M. On the margins of the world. Malden: Polity Press, 2008.

AGIER, M. Onde se inventa a cidade do amanhã? Deslocamentos, margens e dinâmicas das fronteiras urbanas. In: GLEDHILL, J.; HITA, M. G.; PERELMAN, M. (Org.). Disputas em torno do espaço urbano: processos de [re]produção/construção e apropriação da cidade. Salvador: EDUFBA, 2017. p. 411-426.

ALMEIDA, R.; D’ANDREA, T.; DE LUCCA, D. Situações periféricas: etnografia comparada de pobrezas urbanas. Novos Estudos Cebrap, São Paulo, v. 28, p. 109-130, 2008.

ALSAYYAD, N. Urban Informality as a "New" Way of Life. In: ALSAYYAD, N.; ROY, A. (Ed.). Urban Informality: Transnational Perspectives from the Middle East, Latin America and South Asia. Maryland: Lexington Books, 2004. p. 7-31.

ANZALDUA, G. Borderlands/La frontera. San Francisco: Aunt Lute Books, 1987.

ARANTES, A. A guerra dos lugares: mapeando zonas de turbulência. In: ARANTES, A. Paisagens paulistanas: transformações do espaço público. Campinas: Editora Unicamp, 2000.

198 BENJAMIN, W. Passagens. Belo Horizonte: Editora UFMG, 2006. 
BIRMAN, P. Apresentação. In: CUNHA, N. da; FELTRAN, G. de S. (Org.). Sobre periferias: novos conflitos no Brasil contemporâneo. Rio de Janeiro: Lamparina; FAPERJ, 2013.

BONDUKI, N; ROLNIK, R. Periferias: ocupação do espaço e reprodução da força de trabalho. São Paulo: FAU/USP, 1979. (Caderno de Estudos e Pesquisas Fupam).

BORSANI, M. E.; QUINTERO, P. (Comp.). Los desafios decoloniales de nuestros días: pensar en colectivo. Neuquén: Educo - Editorial de la Universidad Nacional del Comahue, 2014.

CALDEIRA, T. P. do R. A politica dos outros: o cotidiano dos moradores de periferia e o que pensam do poder e dos poderosos. São Paulo: Brasiliense, 1984.

CASTELLS, M. A questão urbana. Rio de Janeiro: Paz e Terra, 1983.

CASTRO-GÓMEZ, S.; GUARDIOLA-RIVERA, Ó. E.; BENAVIDES, C. R. M. de. Pensar (en) Los Intersticios: teoría y práctica de la crítica poscolonial. Bogotá: Pensar, 1999.

CORAGGiO, J. L. Pesquisa urbana e projeto popular. Espaço $\mathscr{E}$ Debates, São Paulo, n. 26, ano 9, p. 23-39, 1989.

CORDEIRO, G. Í.; FRÚGOli JUNIOR, H. Prefácio. In: AGIER, M. Antropologia da cidade: lugares, situações, movimentos. São Paulo: Terceiro Nome, 2011. p. 9-30.

CUNHA, N. V. da; FELTRAN, G. de S. (Org.). Sobre periferias: novos conflitos no Brasil contemporâneo. Rio de Janeiro: Faperj/Lamparina, 2013.

DAS, V.; POOLE, D. (Ed.). Anthropology in the margins of the state. New Mexico: School of American Research, 2004.

FELTRAN, G. de S. Introdução. Lua Nova, São Paulo, n. 79, p. 9-13, 2010.

FELTRAN, G. de S. et al. As margens da cidade: grupos urbanos 'marginais', política e violência no estado de São Paulo. São Carlos, UFSCar, 2011. Relatório parcial de pesquisa. Não publicado. 
FRÚGOLI JUNIOR, H. O urbano em questão na antropologia: interfaces com a sociologia. Revista de Antropologia, São Paulo, v. 48, n. 1, p. 133-165, 2005.

GAGNEBIN, J. M. Limiar, aura, rememoração: ensaios sobre Walter Benjamin. São Paulo: Ed. 34, 2014.

GLEDHILL, J.; HITA, M. G.; PERELMAN, M. Introdução: a questão urbana, hoje. In: GLEDHILL, J.; HITA, M. G.; PERELMAN, M. (Org.). Disputas em torno do espaço urbano: processos de [re]produção/construção e apropriação da cidade. Salvador: EDUFBA, 2017. p. 9-24

HARVEY, D. Neoliberalism as Creative Destruction. The Annals of the American Academy of Political and Social Science, Philadelphia, v. 610, n. 1, p. 21-44, 2007.

HIRATA, D. V. Sobreviver na adversidade: entre o mercado e a vida. 2010. 367 f. Tese (Doutorado em Sociologia) - Faculdade de Filosofia, Letras e Ciências Humanas, Universidade de São Paulo, São Paulo, 2010. v. 1.

JOSEPH, I. Paisagens urbanas, coisas públicas. Caderno CRH, Salvador, n. 30/31, p. 11- 40, jan./dez. 1999.

KOLOSSOV, V. Border Studies: Changing Perspectives and Theoretical Approaches. Geopolitics, [S.1.], v. 10, n. 4, p. 606-632, 2005.

KOWARICK, L. Escritos urbanos. São Paulo: Ed. 34, 2000.

KOWARICK, L.; BRANT, V. C. (Coord). São Paulo, 1975: crescimento e pobreza. São Paulo: Loyola, 1975.

LAGO, L. C. do. Favela-loteamento: re-conceituando os termos da ilegalidade e da segregação urbana. In: ENCONTRO NACIONAL DA ANPUR, 10., 2003, Belo Horizonte. Anais... Belo Horizonte: ANPUR, 2003.

LANDER, E. (Comp.). La colonialidad del saber: eurocentrismo y ciencias sociales: perspectivas latinoamericanas. Buenos Aires: CLACSO, 2000.

LEPETIT, B. Por uma nova história urbana. São Paulo: Edusp, 2001.

LEWIS, O. Five Families: Mexican case studies in the culture of poverty.

200 New York: The New American Library; Toronto: Mentor Book, 1959. 
LOJKINE, J. O estado capitalista e a questão urbana. São Paulo: Martins Fontes, 1981.

MAGNANI, J. G. C. De perto e de dentro: notas para uma etnografia urbana. Revista Brasileira de Ciências Sociais, São Paulo, v. 17, n. 49, p. 11-29, 2002.

MARICATO, E. (Org.). A produção capitalista da casa (e da cidade) no Brasil industrial. São Paulo: Alfa-Omega, 1979.

MARQUES, E.; BICHIR, R. Estado e espaço urbano: revisitando criticamente as explicações sobre as políticas urbanas. Revista de Sociologia e Política, Curitiba, n. 16, p. 9-29, jun. 2001.

MEZZADRA, S.; NEILSON, B. Border as Method or The Multiplication of Labor. Durham: Duke University Press, 2013.

MIGNOLO, W. Os esplendores e as misérias da 'ciência': colonialidade, geopolítica do conhecimento e pluri-versalidade epistémica. In: SANTOS, B. de S. (Org.). Conhecimento prudente para uma vida decente: "Um discurso sobre as ciências” revisitado. Porto: Edições Afrontamento, 2003a. p. 631-672.

MIGNOLO, W. Histórias locais/projetos globais: colonialidade, saberes subalternos e pensamento liminar. Belo Horizonte: Editora UFMG, 2003 b.

MIGNOLO, W.; TLOSTANOVA, M. V. Theorizing from the Borders: Shifting to Geo- and Body-Politics of Knowledge. European Journal of Social Theory, London, v. 9, n. 2, p. 205-222, 2006.

MORAÑA, M.; DUSSEL, E.; JÁUREGUI, C. A. (Ed.). Coloniality at Large: Latin America and the Postcolonial Debate. Durham: Duke University Press, 2008.

OLIVEIRA, F. de. A economia brasileira: crítica à razão dualista. Petrópolis: Vozes, 1972.

PAOLI, M. C.; SADER, E. Sobre 'classes populares' no pensamento sociológico brasileiro: notas de leitura sobre acontecimentos recentes. In: CARDOSO, R. (Org.). A aventura antropológica. São Paulo: Paz e Terra, 1986. p. 39-67. 
PAOLI, M. C.; SADER, E.; TELLES, V. da S. Pensando a classe operária: os trabalhadores sujeitos ao imaginário acadêmico. Revista Brasileira de História, São Paulo, v. 3, n. 6, p. 129-149, 1983.

PERLMAN, J. O mito da marginalidade. Rio de Janeiro: Paz e Terra, 1977.

PERLONGHER, N. O negócio do michê: a prostituição viril. São Paulo: Brasiliense, 1987.

QUIJANO, A. Redefinición de la dependencia y proceso de marginalización social. In: WEFFORT, F., QUIJANO, A. Populismo, marginalización y dependência: ensayos de interpretación sociológica. Costa Rica: Universidad Centroamericana, 1973. p. 180-213.

RAO, V. Slum as theory: the South/Asian city and globalization. Slum as theory: the South/Asian city and globalization. International Journal of Urban and Regional Research, London, v. 30, n. 1, p. 225-232, 2006.

REVEL, J. (Org.). Jogos de escalas: a experiência da microanálise. Rio de Janeiro: Ed FGV, 1998.

RIBEIRO, A. C. T. Dança dos sentidos: na busca de alguns gestos. In: BRITTO, F. D.; JACQUES, P. B. Corpocidade: debates, ações e articulações. Salvador: EDUFBA, 2010.

RIBEIRO, A. C. T. Homens lentos, opacidades e rugosidades. Redobra, Salvador, n. 9, p. 58-71, 2012.

RIBEIRO, L. C. Q.; LAGO, L. C. do. A oposição favela-bairro no espaço social do Rio de Janeiro. São Paulo em Perspectiva, São Paulo, v. 15, n. 1, p. 144-154, 2001.

RIZEK, C. S. Limites e limiares/Corpo e experiência. Redobra, Salvador, v. 3, n.10, p. 33-39, 2012.

RIZEK, C. S. Os sentidos da cidade brasileira: figurações da ordem e de seus avessos. São Paulo, 2003. Relatório de pesquisa. Não publicado.

ROLNIK, R. A cidade e a lei: legislação, política urbana e territórios na 202 cidade de São Paulo. São Paulo: Nobel, 1997. 
ROSA, T. T. Cidades outras: pobreza, moradia e mediações em trajetórias urbanas liminares. 2014. 391 f. Tese (Doutorado em Arquitetura e Urbanismo) - Instituto de Arquitetura e Urbanismo, Universidade de São Paulo, São Carlos, 2014.

ROSA, T. T. Favelas, periferias: uma reflexão sobre conceitos e dicotomias. In: ENCONTRO ANUAL DA ANPOCS, 33., 2009, Caxambu. Anais... Caxambu: ANPOCS, 2009.

ROSA, T. T. Fronteiras em disputa na produção do espaço urbano: a trajetória do 'Gonzaga' de favela a bairro de periferia. 2008. 230 f. Dissertação (Mestrado em História) - Instituto de Filosofia e Ciências Humanas, Universidade Estadual de Campinas, Campinas, 2008.

ROSA, T. T. et al. Liminaridades. In: BRITTO, F. D.; JACQUES, P. B. Corpocidade: gestos urbanos. Salvador: EDUFBA, 2017.

ROY, A. Urban informality: toward an epistemology of planning. Journal of the American Planning Association, Chicago, v. 71, n. 2, p. 147-158, 2005.

ROY, A. Slumdog Cities: Rethinking Subaltern Urbanism. International Journal of Urban and Regional Research, London, v. 35, n. 2, p. 223-238, 2011.

RUI, T.; MARTINEZ, M. M.; FELTRAN, G. S. Novas faces da vida nas ruas. São Carlos: Edufscar, 2016.

SAMPAIO, M. R.; LEMOS, C. Habitação popular paulistana: autoconstrução. São Paulo: FAU/USP, 1978.

SARTI, C. A. A familia como espelho: um estudo sobre a moral dos pobres na periferia de São Paulo. 1994. 215 f. Tese (Doutorado em Antropologia) - Faculdade de Filosofia, Letras e Ciências Humanas, Universidade de São Paulo, São Paulo, 1994.

SILVA, E. A. da. Nas tramas da "cidade ilegal": atores e conflitos em ocupações de terra urbana. 2006. Dissertação (Mestrado em Sociologia) Faculdade de Filosofia, Letras e Ciências Humanas, Universidade de São Paulo, São Paulo, 2006.

SMITH, N. Geografía, diferencia y las políticas de escala. Terra Livre, São Paulo, ano 18, n. 19, p. 27-146, 2002. 
TELLES, V. da S. Debates: a cidade como questão. In: TELLES, V. da S.; CABANES, R. (Org.). Nas tramas da cidade: trajetórias urbanas e seus territórios. São Paulo: Humanitas, 2006. p. 35-64.

TELLES, V. da S. Pósfacio. In: CUNHA, N. DA; FELTRAN, G. de S. (Org.). Sobre periferias: novos conflitos no Brasil contemporâneo. Rio de Janeiro: Lamparina: Faperj, 2013a.

TELLES, V. da S. Prospectando a cidade a partir de suas margens: notas inconclusas sobre uma experiência etnográfica. Contemporânea: Revista de Sociologia da UFSCar, São Carlos, v. 3, n. 2, p. 359-373, 2013b.

TORRES, H. et al. Pobreza e espaço: padrões de segregação em São Paulo. Estudos Avançados, São Paulo, v. 17, n. 47, p. 97-128, 2003.

VALLADARES, L. do P. (Org.). Habitação em questão. Rio de Janeiro: Zahar, 1980.

VALLADARES, L. do P. (Org.). Repensando a habitação no Brasil. Rio de Janeiro: Zahar, 1983.

VALLADARES, L. do P. A invenção da favela: do mito de origem à favela.com. Rio de Janeiro: Editora FGV, 2005.

VARLEY, A. Postcolonialising informality? Environment and Planning D-Society $\mathcal{E}$ Space, [S.1.], v. 31, n. 1, p. 4-22, 2013.

VEKEMANS, R.; VENEGAS, R. Marginalidad, incorporación e integracion. Santiago: DESAL, 1966.

WEIZMAN, E. Hollow Land: Israel's Architecture of Occupation. London: Verso, 2007.

ZALUAR, A. A máquina e a revolta: as organizações populares e o significado da pobreza. São Paulo: Brasiliense, 1985.

ZALUAR, A.; ALVITO, M. Um século de favela. Rio de Janeiro: Editora FGV, 2003. 